\title{
perifèria
}

Número 2, mayo 2005

www.periferia.name

\section{Clientelismo en democracia. Una propuesta para el análisis de las relaciones clientelares a nivel local. ${ }^{1}$}

\author{
Paulo Jablonski Garcia - Universitat Autònoma de Barcelona - \\ Miembro del GRAFO
}

El presente artículo presenta una crítica de la división analítica entre clientelismo moderno y tradicional defendida por diferentes autores. Basándose en el estudio en un municipio del sudoeste gallego llevado a cabo entre los años 2002 y 2004 se elabora una propuesta centrada en tres elementos principales: 1) la diferenciación entre recursos expresivos e instrumentales; 2) la subdivisión de la clientela de un mismo patrón en varios tipos en base a los recursos intercambiados; 3) plantear el estudio de las relaciones clientelares a través de la definición de sus prácticas. La combinación de estos tres elementos permite englobar las relaciones clientelares existentes en el caso de estudio del cual se parte.

Pasan algunos minutos del mediodía y Manolo entra en la Casa do Concello de Sobreira, un municipio del suroeste de Galiza ${ }^{3}$. En el mostrador pregunta por el alcalde. Un funcionario le responde preguntando si tiene cita. Manolo no tiene cita pero le comenta al funcionario que le diga al alcalde que es "Nolo de Peixo", el alcalde ya sabe. El funcionario llama al alcalde por teléfono. En estos momentos el señor alcalde se encuentra reunido, explica dirigiéndose al vecino. No sabe cuanto tardará, pero imagina que no mucho. Manolo decide esperar. Coge el periódico del mostrador y se sienta a hojear la prensa. Al cabo de unos veinte minutos,

\footnotetext{
${ }^{1}$ La investigación en la que se basa este artículo ha sido financiada con la beca FPU AP20023779 del Ministerio de Educación y Ciencia.

${ }^{2}$ GRAFO: Grup de Reserca d'Antropologia Fonamental y Orientada. Enviar correspondencia a: paulo.jablonski@uab.es

${ }^{3}$ Los nombres de las personas y los lugares que mencionamos son ficticios.
} 


\section{perifèria \\ Número 2, mayo 2005 \\ www. periferia.name}

se abre la puerta del despacho del alcalde y sale una señora. Manolo la saluda con normalidad. Hola Odilia, ¿cómo va todo? Bueno... tirando, ya ves. Hay que seguir para adelante. El funcionario le indica a Manolo que ya puede entrar.

En el despacho, el alcalde está sentado en su mesa llena de papeles. Hay otra mesa de mayor tamaño con seis sillas rodeándola. Ésta tiene un cenicero y dos o tres carpetas. El despacho tendrá unos $30 \mathrm{~m}^{2}$. Una de las paredes es un gran ventanal que da a la calle. En otra hay una estantería con algunos libros, trofeos y fotos del alcalde con diversas personalidades políticas. Un bodegón de caza y una foto antigua de la villa cubren la otra pared. La mesa del alcalde está custodiada por una foto de El Rey, una bandera española y otra gallega. Manolo se acerca pisando una alfombra con motivos florales. El alcalde le invita a sentarse en una de las dos sillas dispuestas para las visitas.

Hola, ¿cómo va todo Nolo? ¿Qué tal la familia? Aún pasé el otro día cerca de tu casa... Mientras el alcalde habla, Manolo permanece en silencio. Una vez que aquel finaliza, Manolo le comenta que tiene un problema en el vecindario. La pista de entrada a su casa está en muy mal estado y con las lluvias se convierte en un barrizal. El alcalde asegura que no hay ningún problema, si se entienden bien, no hay problema. La maquinaria de la Diputación está realizando unas obras cerca y él no tendría problema en hablar con "los de arriba" para que se desvíen un poco en el asfaltado. El alcalde le pregunta sobre sus hijos, que edad tienen, si estudian o trabajan. El alcalde comenta que tiene muy buenas relaciones con la Diputación y que mientras esté él ahí no habrá problemas. Se despiden con un apretón de manos. Manolo le comenta al alcalde que cuente con él. El alcalde contesta que eso espera. Al cabo de una semana, la pista de entrada de la casa de Manolo está cubierta por una capa de asfalto. El alcalde se ha puesto en contacto con la Diputación provincial. 


\section{perifèria \\ Número 2, mayo 2005 \\ www. periferia.name}

Esta situación, con personajes imaginarios, es muy frecuente en el contexto en el cual realicé el trabajo de campo para la elaboración de la tesina de doctorado. Un vecino con ciertas necesidades visita al alcalde que, personalmente, se compromete a satisfacer dichas necesidades. Estamos ante una relación que podríamos definir como clientelar en la medida en que cumple con las características que se atribuyen a este tipo de relaciones.

Se trata de una relación básicamente diádica entre dos o más agentes sociales. Cuando escribimos básicamente diádica nos referimos a que la relación no se corresponde estrictamente con una idea de díada bidireccional tal como afirmaba Foster (1961). Boissevain (1966: 25) amplia el espectro sumando una tercera relación. Con todo, en la situación presentada entran en juego un mínimo de tres agentes: Manolo, el alcalde y la Diputación. Scott (1972) admite la díada como relación básica (1986) pero que va más allá en su análisis (1972: 96) apuntando que la relación patrón-cliente puede tomar la forma de cluster que, unidos, constituyen una pirámide. La naturaleza de la relación es objetivamente asimétrica. Existe un diferente control de los recursos (Caciagli, 1996: 18) o, si se prefiere, una diferencia funcional entre patrón y cliente (Cazorla, 1996: 300). Manolo no tiene acceso a los recursos necesarios para asfaltar un camino. Se realiza un intercambio de dos tipos de recursos: instrumentales y expresivos (Lin, 1982) ${ }^{4}$. Los instrumentales vienen definidos por la posibilidad de utilizar la maquinaria de la Diputación y los expresivos por el apoyo tácito que Manolo ofrece al alcalde. El intercambio supone individualizar y particularizar una relación que, en principio, es pública (colectiva) con lo que se configuran redes sociales sin cierre horizontal (Máiz, 1994; 2003). Manolo no acude al alcalde como representante de un colectivo ni el alcalde concede los recursos a un colectivo, sino que el

\footnotetext{
${ }^{4}$ Para temas específicos de clientelismo (Roniger, 1990 citado por Auyero 1999; Máiz, 1994)
} 


\section{perifèria \\ Número 2, mayo 2005 \\ www.periferia.name}

intercambio es individual. La relación definida por el intercambio crea dependencia entre el patrón y el cliente que se mantiene gracias a la satisfacción subjetiva de las partes implicadas en el intercambio. Las dos partes terminan la conversación satisfechos por los logros de la misma. La práctica suele estar bajo sospecha y rodeada de cierto silencio auque no por eso sancionada legalmente (Auyero, 1999; Corzo, 2002a).

Esta situación es frecuente en Sobreira y nos descubre toda una serie de desajustes entre las diferentes conceptualizaciones sobre la evolución del clientelismo consultadas para la realización del marco teórico de la tesina y la realidad que se pretendía analizar. Estos desajustes provienen, básicamente, de dos elementos. En primer lugar, la diferenciación entre un clientelismo tradicional y otro moderno. En segundo lugar, en la idea de algunos autores de que la modernización y la consolidación de la democracia resultaría en la eliminación de las características básicas del llamado clientelismo tradicional.

La realización del trabajo de campo puso en evidencia esta tensión y nos obligó a reformular el marco analítico desde el cual enfocar el fenómeno del clientelismo. La situación presentada tiene lugar en un contexto de democracia consolidada institucional y moralmente. Bien es cierto que la democracia se consolida en un contexto determinado sobre el que se moldea dicha consolidación. En este artículo no trataremos este aspecto de adecuación institucional, sino que nos detendremos en el análisis de las propuestas de diversos autores para finalizar con una propuesta analítica para el estudio de las relaciones clientelares. Comenzaremos por presentar tres propuestas de tipologías sobre el clientelismo.

Graziano (1973: 19-20) establece tres etapas de desarrollo político diferenciadas a las que le asocia un tipo de clientelismo particular a cada una de ellas. El autor apunta condiciones políticas, económicas y culturales 


\section{perifèria \\ Número 2, mayo 2005 \\ www.periferia.name}

como criterios de cambio entre una y otra etapa. La primera etapa se corresponde con la sociedad tradicional caracterizada por relaciones económicas semifeudales, concentración del poder económico, falta de competencia política y una cultura del respeto. Estas condiciones se traducen en la hegemonía del poder de los notables con elementos de legitimidad tradicional, violencia y corrupción. La segunda etapa la denomina sociedad en transición caracterizada por el crecimiento de la mercantilización de la economía, nuevas actividades económicas privadas e inversiones públicas, aparición de partidos políticos y contiendas electorales y desaparición del respeto tradicional junto a una falta de legitimidad de los nuevos líderes políticos. Estas condiciones se traducen en un patronazgo de partido basado en los recursos públicos, conexiones externas de los partidos, uso privado de los sindicatos, corrupción y violencia. La tercera etapa se corresponde con lo que el autor denomina sociedad movilizada. Las principales características son la presencia de un mercado capitalista, políticas de desarrollo planificado, hegemonía de los partidos de masas y su legitimidad. Los instrumentos de control político son los partidos de masa centralizados, movilización ideológica y política de las masas, sindicatos de intereses de clase y la violencia de clase.

A lo largo del artículo citado, así como en Graziano (1976: 164-165), el autor se fija en los dos tipos extremos de clientelismo, a saber, el tradicional y el moderno o party-directed patronage. La etapa en transición se convierte en un puente entre esos dos grandes tipos de clientelismo. Las diferencias más importantes entre ellos son que, mientras en el tradicional las relaciones se establecen con un único patrón, la relación es exclusivamente vertical, cara a cara y existe un lazo importante de afectividad con el patrón, en el clientelismo moderno la relación se convierte en anónima ya que las relaciones son entre grupos y no individuos. 


\section{perifèria \\ Número 2, mayo 2005 \\ www. periferia.name}

Por otro lado, Lemarchand y Legg (1972) diferencian tres tipos de sistemas clientelares: feudal, patrimonial e industrial. Cada uno de ellos lo defininen por la combinación de cuatro variables: 1) valor y alcance de la movilización social; 2) el alcance de la penetración e influencia de las estructuras gubernamentales; 3) grado de diferenciación entre los niveles del sistema; 4) la capacidad distribuidora del sistema.

En el sistema feudal el clientelismo se caracteriza por una institucionalización y formalización acentuada de la relación diádica entre el patrón y el cliente, señor-vasallo, que toma forma contractual. Esta relación se apoya en el respeto y afecto intercambiándose protección y servicios mutuamente.

En el sistema patrimonial los autores apuntan varias diferencias respecto al anterior sistema: el sistema político opera a través de una administración especializada y un gobierno elegido por un jefe, el grado de formalización de la relación patrón-cliente es mucho menor, la relación patrón-cliente es un prerrequisito para ser designado para el gobierno y la relación es menos personal. Los autores distinguen dos subsistemas dentro del patrimonialista.

En primer lugar, el tradicional donde la relación clientelar es transversal a todo el sistema político, no existe diferenciación entre los diferentes niveles del sistema y su capacidad distribuidora es limitada. Estas características sitúan al jefe (ruler) como único centro. El segundo subtipo lo denominan modernizado (modernizing) donde la movilidad social provoca ciertas discontinuidades en la red clientelar sobre todo en el centro del sistema. Este subsistema cuenta con una presencia importante de relaciones patrón-cliente del tipo tradicional en la periferia. Las del centro del sistema no son monolíticas. Esta característica provoca la competencia entre diferentes patrones. El principal criterio de diferenciación que apuntan los autores es el grado de cambio en las estructuras estatales en términos de modernización. 


\section{perifèria}

Número 2, mayo 2005

www.periferia.name

El tercer sistema que mencionan los autores es el industrial. En este periodo se da una gran movilidad social, una diferenciación de los niveles del sistema, una alta capacidad de distribución y unas relaciones entre los administrados y los administradores de tipo legal-racional. En este contexto existe clientelismo que es explicado alegando que la modernización es discontinua y que existen vestigios del pasado clientelar que permanecen. Con todo, la razón más importante en palabras de Corzo (2002a: 48) es que "la movilización social provocaba que la sociedad penetrase en las estructuras gubernamentales creando canales de contacto entre los individuos y la administración. La disfunción radicó en que la relación afectiva condicionó, sobremanera, las posibles actuaciones gubernamentales, porque de ella dependía el acceso a un empleo, a un ascenso, o a cualquier recurso. Esto hizo que las bases llegasen a comprometerse de forma incondicional con sus líderes tendiendo estos a controlar a las mismas. En este momento histórico (la revolución industrial) se daba la circunstancia de que, a la vez, la elite económica ocupaba el espacio de política. $Y$ esto facilitó que los canales efectivos para conseguir un recurso público fuesen los que se hacían a través de intercambios o clientelas tradicionales o particularistas."

Lemarchand y Legg (1972) no presentan la tipología como una secuencia de la evolución necesaria de los sistemas clientelares sino que aceptan que pueda haber desincronización y combinación de diferentes variables de tipos diversos en un contexto determinado. Con todo, asocian cada etapa histórica a un tipo de clientelismo entendiéndolo como un elemento propio del subdesarrollo y con tendencia a desaparecer.

Siguiendo el análisis histórico del clientelismo, para el Estado español las propuestas contienen la diferenciación general de clientelismo tradicional versus clientelismo moderno. Cazorla (1992) traza una línea desde el caciquismo-clientelismo tradicional presente en la época de la Restauración hasta el clientelismo de partido propio de la democracia. El autor pasa por 


\section{perifèria \\ Número 2, mayo 2005 \\ www. periferia.name}

alto la época del franquismo de la que menciona que "desarrolló sus propias variedades clientelares en un sistema no competitivo" (1992: 16). En otro artículo de 1996 afina más en la diferenciación del clientelismo de partido apuntando dos subtipos: "laboral, caracterizado por la distribución de puestos el sector público o para público, y el clientelismo concesional, que se expresa en el otorgamiento de concesiones (...) licencias de obra o de explotación, juegos, u obtención de subvenciones o exenciones de relevancia colectiva o individual" (1996: 307).

Robles Egea (1996) expone una secuencia casi idéntica que comienza en el caciquismo decimonónico o clásico de finales del siglo XIX y comienzos del $\mathrm{XX}$, un clientelismo de Estado-partido único propio del régimen franquista caracterizado por ser "burocrático, institucional e ideológico" (1996: 242) que controlaba la maquinaria del sistema asegurando su propia permanencia aun cuando en la periferia los jefes locales hicieran y deshicieran a gusto. A diferencia de Cazorla, Robles Egea sitúa el inicio del clientelismo de partido en la II República (1996: 250) "que resurgirá después de la muerte de Franco".

Corzo (2002a; 2002b) nos ofrece una propuesta analítica centrada en el clientelismo moderno al que ella se refiere como clientelismo político. La autora nos presenta un total de tres tipos de relación clientelar basándose en los bienes y recursos intercambiados. Todos ellos específicos de contextos democráticos. "Las relaciones de clientela política se manifiestan de tres formas relacionadas entre si pero que diferenciamos para mejorar su comprensión:

1. Clientelismo electoral: La relación entre un candidato y el electorado, y los elementos que influyen en el voto si se enmarca en un contexto democrático. 


\section{perifèria \\ Número 2, mayo 2005 \\ www. periferia.name}

2. Clientelismo de partido: El formado por el intercambio de recursos públicos entre actores de un mismo partido a cambio de apoyos dentro y fuera de este.

3. Clientelismo burocrático: Relaciones de intercambio entre actores de un partido, a partir de la distribución de recursos y servicios públicos, para beneficiar bien a electores, a instituciones (partidos, sindicatos, empresas, grupos corporativos...) o al propio líder político." ${ }^{5}$

La autora añade más abajo que "difícilmente encontramos en estado puro una de las relaciones. Suelen presentarse formando una red aunque cada uno de los intercambios se da entre dos actores: político y cliente". Su criterio de diferenciación se basa en el elemento de intercambio. En el primer caso denominado clientelismo electoral son votos por promesas, recursos públicos por apoyos en el segundo, siendo este clientelismo de partido y recursos públicos por apoyos en el tercero llamado clientelismo burocrático (Corzo, 2002a: 77-79).

Se trata de una propuesta que supera a la de Cazorla (1992; 1996) ya que siguen el mismo criterio del qué se intercambia pero afinando más la puntería analítica. Éste diferenciaba entre clientelismo laboral y concesional con lo que obviaba que este tipo de intercambio sólo puede ser realizado por un partido con responsabilidades ejecutivas ya que sólo éstas ofrecen el acceso a los recursos apuntados. En este sentido la división de Cazorla queda integrada en el clientelismo burocrático de Corzo.

En las secuencias de Graziano y Lemarchand y Legg observamos un proceso paralelo que nos lleva de un clientelismo tradicional o personalista en términos de Roniger (1994: 3) "basado en relaciones cara a cara con lazos normativos de deferencia y lealtad entre patrón y cliente", de fuerte

\footnotetext{
5 La enumeración es nuestra.
} 


\author{
perifèria \\ Número 2, mayo 2005 \\ www. periferia.name
}

carácter personalista, con relaciones verticales a otro moderno donde se impone el anonimato, los incentivos selectivos (Graziano, 1976, Máiz, 1994, 1996), pérdida de autonomía de los patronos (Cazorla, 1992), los intercambios entre grupos y no personas, lo cual no significa que, en cierto sentido y a un nivel diferente que el anterior, sea particularista (Cazorla, 1996: 299).

Fijémonos en la contraposición de los dos grandes clientelismos en el horizonte de nuestro caso de Sobreira. El primero de los tipos, tal y como indicamos más arriba, hace referencia a una realidad donde existe un elemento central (patrón) que, mediante una relación diádica, cara a cara, asimétrica, de intercambio de lealtad por protección y bienes materiales, controla el sistema político. En el segundo tipo, esta realidad se difumina en el anonimato, la distribución colectiva de la relación clientelar donde el patrón se convierte en un ente colectivo llamado partido y los clientes en grupos corporativos como asociaciones, sindicatos, comunidades, etc. El primero parece que se centra en nivel micro, atendiendo a las relaciones particulares del clientelismo mientras que el segundo asciende a un nivel meso y macro donde es preciso incluir diferentes niveles de análisis como pueden ser la local, regional o estatal.

Esta diferencia no se debe de confundir con la que menciona Máiz (1996: 43-45) con el doble cambio que experimenta el acercamiento de la problemática clientelar a finales de los años 70 . El interés de la ciencia política por el clientelismo, según el autor, modifica la perspectiva “desde el nivel micro al nivel macro del fenómeno, y desde una perspectiva de integración social a una de integración sistémica". La perspectiva micro y de integración social sería propia de la antropología y, la otra, de perspectiva macro y de integración sistémica de la ciencia política (Caciagli, 1996). Esta observación ya fuera realizada por Weingrod (1968) señalando más tarde la necesidad de superar los análisis de integración social para adoptar una perspectiva procesual que procurase el lugar del poder en la relación 


\section{perifèria \\ Número 2, mayo 2005 \\ www.periferia.name}

patrón-cliente (Weingrod, 1986). Scott (1972) también apunta la necesidad de superar los estudios micro realizados por la antropología. Con todo, es Eric Wolf quién, en 1956, se refiere a los intermediarios como eslabones de enlace entra la comunidad (community-oriented groups) y el estado (nation-oriented groups) rompiendo la burbuja de la dimensión micro de este tipo de estudios.

Si tomamos como referencia el contexto de Manolo y el señor alcalde, tendríamos dificultades en situar las relaciones políticas que observamos en uno u otro lado de la línea divisoria. En términos institucionales habría que situarlo dentro del clientelismo moderno. La monarquía parlamentaria impide formalmente la práctica del clientelismo en los términos tradicionales ya que se presupone un Estado de derecho. El estado "racional-burocrático-democráticas" en palabras de Adler Lomnitz et alli (1990: 275-332). Se podrían exponer ejemplos de prácticas de diferentes situaciones propias de cada uno de los subtipos de clientelismo señalados por Corzo.

Clientelismo electoral en la medida en que existen procesos electorales con sus respectivas campañas y el gobierno entabla reuniones con diferentes grupos del municipio donde se intercambian votos por promesas o, mejor dicho, promesas por intenciones de voto.

El clientelismo de partido sería, a la luz del trabajo de campo realizado, más complicado de mostrar. Con todo, Lagares $(1999,2003)$ ha demostrado las potencialidades clientelares de la estructura partidaria del PP gallego, partido del gobierno de Sobreira en la fecha del estudio. Comenta la autora que "o carácter presidencialista que domina toda a organización contribúe ao xurdimento [de] feudos, posto que limita a capacidade de acción dos órganos colexiados rexionais sobre a acción político-organizativa dos líderes provinciais" (2003: 55). Apunta que la débil institucionalización del partido en Galiza es fruto de la inclusión de diferentes familias en su seno. A ello hay que sumarle las labores de 


\section{perifèria \\ Número 2, mayo 2005 \\ www. periferia.name}

gobierno que limita la atención ejercida sobre el propio partido y el liderazgo absoluto de Manuel Fraga (62-63). A esta situación hay que sumarle la presencia de la Diputaciones provinciales "como instrumento de control e potenciación dos municipios" (55-56).

El tercer subtipo de clientelismo señalado por Corzo se refiere al burocrático. Los ejemplos son frecuentes y como indicador son válidas las reiteradas quejas de la oposición mostradas en sus boletines informativos o en intervenciones en las sesiones plenarias del Ayuntamiento sobre el uso particular de los bienes públicos.

En la otra mano, las relaciones clientelares identificadas como tradicionales no son ajenas a la práctica política del municipio. Existe una extendida visión particularista de la práctica política, relaciones diádicas asimétricas cara a cara entre los miembros del equipo de gobierno y la población. El caso de Manolo es frecuente en el municipio, donde el alcalde atiende personalmente en su despacho las peticiones de los vecinos. Resuelve de forma individual problemas colectivos como puede ser el alumbrado público atendiendo a cada petición por separado. Observamos una serie de elementos que nos indican la presencia de importantes trazos propios del clientelismo tradicional y que nos alejan del que se supone debería imperar.

Como ya hemos escrito, Corzo (2002a; 2002b) establece una diferenciación para el clientelismo moderno en tres niveles. La autora advierte que esta diferenciación es analítica ya que en la realidad observada cada una de estas variedades de clientelismo se imbrican llegando a dificultar su distinción. Esta propuesta no menciona de una forma explícita al clientelismo tradicional pero presupone que existe ya que define al moderno en contraposición al primero. Esta propuesta toma el clientelismo moderno como un todo compacto y la propuesta analítica no contempla la posibilidad de interferencias del clientelismo tradicional. Lemarchand y Legg presentaban la presencia de aspectos del clientelismo tradicional como 


\section{perifèria \\ Número 2, mayo 2005 \\ www. periferia.name}

survivals. Esta addenda no nos satisface. Admitiendo que la diferenciación clientelismo tradicional-moderno es de naturaleza analítica u operacional, no podemos obviar que las interconexiones entre uno y otro, por lo menos en nuestro caso de estudio, obligan a puntualizar matices e introducir otras variables en el modelo.

Comencemos por un artículo de Scott (1972). La diferencia que establece entre lazos instrumentales y afectivos entre clientela y patrón le lleva a diferenciar entre el núcleo y la periferia (core and periphery) de esa misma relación. Estos dos diferentes niveles de clientela definen dos subtipos de relación clientelar. El núcleo, en palabras de Scott, está fuertemente ligado al patrón. Sus lazos son intensamente afectivos e instrumentales a un tiempo de tal forma que se presentan como indestructibles. Por otro lado, la periferia de la clientela establece una relación estable pero no inmutable, de lazos principalmente instrumentales con el patrón.

Esta diferenciación la encontramos adaptada en el artículo de Auyero (1999) sobre los punteros del Partido peronista en una barriada bonaerense en Argentina. Este autor distingue entre un círculo interno y otro externo (inner circle y outer circle). El primero se caracteriza, siguiendo los trabajos de Granovetter, por la presencia de lazos fuertes con el patrón. El círculo externo de la clientela contaría con potenciales clientes o clientes esporádicos y su relación se materializa a través de lazos débiles. Tanto Scott como Auyero apuntan que la distinción es puramente analítica. "En realidad, la línea que los separa es porosa y móvil” (Auyero, 1999: 325).

Las dos propuestas, aunque no idénticas, son similares en cuanto que puntualizan la heterogeneidad de la clientela $y$, con ello, las diferentes relaciones clientelares que se establecen entre el patrón y cada una de ellas. A diferencia del criterio que establece Corzo para diferenciar entre clientelismo electoral, de partido y burocrático, que no incluye la relación entre el cliente y el patrón, los textos referidos introducen explícitamente 


\section{perifèria \\ Número 2, mayo 2005 \\ www. periferia.name}

este matiz. Si bien los autores citados interpretan esta heterogeneidad dentro de los tipos de clientelismo señalados, nosotros nos detendremos en este punto y quisiéramos dar un paso más. Vayamos por partes.

Más arriba diferenciábamos entre recursos instrumentales y expresivos (Lin, 1982). Los primeros hacen referencia a los recursos de tipo económico, material que ofrece normalmente el patrón y los segundos a la confianza-lealtad ofrecida casi siempre por el cliente. Los recursos expresivos son fundamentales para diferenciar una clientela de la otra. Una de las diferencias fundamentales entre el núcleo y la periferia de una clientela es el diferencial de recursos expresivos intercambiados. El intercambio instrumental va acompañado de un fuerte contenido de lealtad y confianza, ese algo más que afianza la relación que distingue a la reciprocidad de otros intercambios (Narotzky, 2004: 69-143). Si bien es cierto que los recursos expresivos se basan, en cierto sentido, principalmente en el intercambio instrumental y las dependencias derivadas de éste, también lo es la necesidad de diferenciar grados de lealtad y confianza. La distinción entre el núcleo y la periferia de Scott o la secuencia de círculos concéntricos de Auyero nos darán pistas en este sentido.

Si comparamos la fidelidad que muestra la clientela del círculo interno de los punteros del Partido peronista descrito por Auyero con las del círculo externo nos encontramos en los extremos de una línea. Si por el contrario lo que comparamos son los recursos instrumentales, nos encontramos diferencias pero éstas no son extremas. El intercambio, si se produce entre el patrón y la clientela del círculo externo es, en términos de los recursos instrumentales, muy semejante en grado a la intercambiada en el círculo interno. El propio Auyero (1999: 321-322) propone que "la proximidad al poder convierte al orden político menos arbitrario" debido al intenso intercambio de recursos expresivos. La presencia más intensa de recursos expresivos no siempre es sinónimo de un mayor intercambio de recursos instrumentales sino que puede generar expectativas e ilusiones de 


\section{perifèria \\ Número 2, mayo 2005 \\ www. periferia.name}

disfrutar de los recursos que substituyan al intercambio físico (Günes-Ayata, 1994: 22). Serán, entonces, los recursos expresivos los que marquen la diferencia fundamental entre estos dos grupos de clientela.

La lealtad y confianza que se aprecia en la clientela más próxima se difumina a medida que nos alejamos. Podríamos decir que el grado de dependencia y el tipo de relación que se establece entre este círculo cercano contiene elementos cercanos a los que caracterizábamos como clientelismo tradicional. Es decir, relación cara a cara, alto grado de dependencia, relaciones verticales personalizadas. En el otro lado, el tipo de relación que se establece con los círculos exteriores se aproxima al clientelismo moderno en la medida en que se basa en incentivos selectivos, mayor grado de autonomía y anonimato por parte de los clientes. Por lo tanto, en un momento dado, trazos de clientelismos diferentes podrían estar conviviendo conjuntamente. Ahora ya no como un estadio de transición (Graziano, 1973; Lemarchand y Legg, 1972) sino como un tipo de clientelismo prolongado en el tiempo con unas características determinadas.

En esta primera aproximación al fenómeno del clientelismo, resulta algo incómodo utilizar las tipologías presentadas anteriormente. Del mismo modo, el contexto democrático en el cual realizamos el trabajo de campo nos impide hablar de un sistema clientelar en el sentido de sistema de dominación (Vargas, 1993) ya que las relaciones políticas ofrecen espacios para el intercambio programático (Kitschelt, 2000). La caracterización de la práctica política no se agota con el clientelismo sino que se puede analizar "en términos de distribución de beneficios y costes entre los electores, mediante políticas públicas y criterios objetivos y universalistas, sean o no votantes del partido" (Máiz, 2003: 7). El contexto legal y moral de la monarquía parlamentaria así lo establece. Con todo, una y otra opción no agotan el análisis de la relación de la administración local con los administrados. 


\section{perifèria \\ Número 2, mayo 2005 \\ www. periferia.name}

Nosotros hemos optado por centrar el estudio del clientelismo en torno a las prácticas clientelares. La propuesta analítica que exponemos a continuación se sirve de la triple distinción que del clientelismo político realiza Susana Corzo (2002a): electoral, burocrático y de partido. Nosotros adoptaremos esta distinción para ordenar las prácticas clientelares. Esta es una clasificación analítica y en la realidad las diferentes prácticas se imbrican de forma que a veces es difícil realizar las distinciones oportunas.

Prácticas clientelares electorales: Son aquellas en las que el elector intercambia su voto por promesas electorales. En su caso, el voto puede constituir el pago de algún favor pasado o la expresión de lealtad.

1. Distribución territorial de la candidatura. Asociación territorial de cada persona candidata al mismo o mayor nivel que a su opción política.

2. Campaña electoral personalizada. Preeminencia de los vínculos individuales sobre los colectivos.

3. Reparto selectivo de papeletas de voto. Variante autónoma de la anterior práctica.

4. Acarrexo de votos. Transporte de electores a los colegios electorales por parte de afines de una opción política

Prácticas clientelares burocráticas: "El cliente, como individuo agregado o parte del grupo, concede su apoyo al intermediario del que dispone para relacionarse con el poder a cambio de ser tratado positiva y preferencialmente como grupo objetivo en sus actuaciones" (Corzo, 2002a: 62). 


\section{perifèria \\ Número 2, mayo 2005 \\ www. periferia.name}

1. Política de concesión selectiva de empleo público. Oferta limitada a círculos próximos.

2. Política de distribución selectiva de recursos y bienes municipales. Oferta condicionada a la clientela

3. Política de concesión selectiva de licencias de obra. Oferta condicionada a la clientela

4. Potenciación de canales particularizados de atención entre la ciudadanía y la administración.

Prácticas clientelares de partido: “El cliente da su apoyo a un líder, facción o corriente a cambio de obtener un beneficio en la distribución de los recursos y servicios públicos cuando esta facción, líder o corriente alcance el poder" (Corzo, 2002a: 62).

En la medida en que nuestro estudio se redujo al análisis a nivel local, no poseemos con elementos para profundizar en este aspecto.

Las prácticas clientelares representan una serie de situaciones que se presentan en la práctica política en diferente grado dependiendo de los recursos intercambiados. La distinción de estas prácticas está en relación con la distinción de los círculos concéntricos de Auyero y Scott. La inclusión de esta variable nos permitirá diferenciar clientelas pero, sobre todo, visualizar la combinación de prácticas clientelares que, en términos de tipologías clientelares, pertenecerían a diferentes tipos.

El estudio del clientelismo tiene que explicar las relaciones entre los Manolos y los señores alcaldes y los señores alcaldes y las Diputaciones que, sin renegar de su condición de ciudadanos e instituciones de un sistema democrático, mantienen relaciones cara a cara intercambiando votos por favores. En las democracias de partidos de masas donde semeja 


\section{perifèria \\ Número 2, mayo 2005 \\ www. periferia.name}

que todo se cocina en los grandes medios de comunicación no podemos perder de vista el contacto cara a cara entre patrones y clientes (Auyerio, 1997: 19).

En las sociedades contemporáneas, con democracias consolidadas, es difícil encontrar contextos plenamente clientelares. La atención la debemos situar en la búsqueda de elementos que nos indiquen la existencia de relaciones clientelares amagadas entre los vínculos programáticos que establece el marco administrativo. Nosotros proponemos buscar estas prácticas clientelares y distinguir diferentes tipos de clientela que, según los recursos intercambiados, serán protagonistas de unas u otras prácticas.

\section{Bibliografía}

Adler Lomnitz, L., Lomnitz Adler, C. y Adler, I. (1990). “El fondo y la forma. La compaña presidencial del PRI en 1988" en Adler Lomnitz, L. (1994): Redes sociales, cultura y poder: ensayos de antropología latinoamericana. México: FLACSO, pp. 275-332.

Auyero, Javier (1997). "Estudios sobre clientelismo político contemporáneo" en Auyero, Javier (Comp.) ¿Favores por votos?. Estudios sobre clientelismo político contemporáneo. Buenos Aires: Losada, pp. 15-39.

Auyero, Javier (1999). "From the client's point of view: How poor people perceive and evaluate political clientelism". Theory and Society no 28 , pp. 297-334.

Boissevain, Jeremy (1966). "Patronage in Sicily". Man, New series, Vol. 1, no. 1, pp. 18-33

Caciagli, Mario. (1996). Clientelismo, corrupción y criminalidad organizada. Madrid: Centro de Estudios Constitucionales. 


\section{perifèria \\ Número 2, mayo 2005 \\ www. periferia.name}

Cazorla, J. (1992). Del clientelismo tradicional al clientelismo de partido: evolución y características. Barcelona: Institut de Ciències Politiques i Socials, WP ำ55.

Cazorla Pérez, J. (1996). "El clientelismo de partido en la españa de hoy: una disfunción de la democracia" en Robles Egea, A. (Comp.) Política en penumbra. Patronazgo y clientelismo políticos en la España contemporánea. Madrid: S.XXI, pp. 291-310.

Corzo Fernández, Susana (2002a). El clientelismo político. El plan de empleo rural en Andalucía: un estudio de caso. Granada: Biblioteca de Ciencias políticas y Sociología, Universidad de Granada.

Corzo Fernández, Susana (2002b). El clientelismo político como intercambio. Barcelona: Institut de Ciències Polítiques i Socials, WP no. 206. Foster, G.M. (1961). "The dyadic contract: a model for the social structure of a Mexican peasant village". American Anthropologist, № 63. pp. 11731192.

Graziano, Luigi (1973). "Patron clients relationships in southern Italy". European J ournal of Political Research №1, pp. 1-34.

Graziano, Luigi (1976). "A conceptual framwork for the study of clientelisc behavior". European J ournal of Political Research no 4, pp. 149-174.

Günes-Ayata, Ayse (1994). “Clientelism: Premodern, Modern, Postmodern" en Roniger, Luis y Günes-Ayata, Ayse (Ed.) Democracy, clientelism and Civil Society. London: Lynne Rienner Publishers, pp. 19-28.

Kitschelt, H. (2002). "Linkages between citizzen and po litician in democratic polities". Comparative Political Studies. Vol. 33, no 6/7, pp. 845-879.

Lagares Díez, Nieves (1999). Génesis y desarrollo del Partido Popular en Galicia. Madrid :Tecnos. 


\section{perifèria \\ Número 2, mayo 2005 \\ www. periferia.name}

Lagares Díez, Nieves (2003). "O Partido Popular de Galicia". En: Rivera Otero (Coord.) Os partidos políticos en Galicia. Vigo: Xerais, pp. 19-99.

Lemarchand, R. y Legg, K. (1972). "Political clientelism and development: A preliminary analysis". Comparative Politics, Vol. 4, no 2, pp. 149-179.

Lin, Nan (1982). "Social Resources and Instrumental Action". En Marsden, Peter V. y Lin, Nan. Social Structure and Network Analysis. Beverly Hills/London/NewDelhi: Sage Publications, pp.131-145.

Máiz, Ramón, (1994). “Estructura y acción: elementos para un modelo de análisis micropolítico del clientelismo". RIS, no 8-9, pp. 189-215.

Máiz, Ramón (1996). "Estrategia e institución: El análisis de las dimensiones macro del clientelismo político" en Robles Egea, A. (Comp.) Política en penumbra. Patronazgo y clientelismo políticos en la España contemporánea. Madrid: S.XXI, pp. 43-70.

Máiz, Ramón (2003). Jama, Caleta y Camello: La corrupción como mecanismo de autorrefuerzo del clientelismo político. Separata de la Revista Mexicana de Sociología, Año 65, no 1 (Marzo), pp.3-39.

Narotzky, Susana (2004) [1997]. "Distribución y entercambio" en Narotzky, Susana. Antropología económica. Nuevastenencias. Barcelona: Melusina, pp. $69-144$

Robles Egea, A. (1996). "Sistemas políticos, mutaciones y modelos de las relaciones de patronazgo y clientelismo en la España del siglo XX" en Robles Egea, A. (Comp.). Política en penumbra. Patronazgo y clientelismo políticos en la España contemporánea. Madrid: S.XXI, pp. 229-252.

Roniguer, Luis (1994). "The comparative Study os Clientelism and the Changing Nature of Civil Society" en Roniger, Luis y Günes-Ayata, Ayse (Eds.). Democracy, clientelism and Civil Society. London: Lynne Rienner Publishers, pp. 1-18. 


\section{perifèria \\ Número 2, mayo 2005 \\ www. periferia.name}

Roniger, Luis y Günes-Ayata, Ayse (1994). Democracy, clientelism and Civil Society. London: Lynne Rienner Publishers.

Roniger, Luis (1990). Hierarchy and Trust in Modern Mexico and Brazil. New York, Praeger.

San Román, Teresa, González Aurora y Díaz, Aurelio (2004). Presupuestos del GRAFO sobre investigación en Antropología. Documento policopiado de acceso restringido.

Scott, J.C. (1972). "Patron-client politics and political change in southeast Asia". American Political Science Review, no 66, pp. 91-113.

Scott, James (1986) [1977]. ¿Patronazgo o explotación? en Gellner, Ernst (Ed.): Patrones y clientes. Madrid: Júcar, pp. 35-61.

Vargas González, Pablo (1993). Lealtades de sumisión. Caciquismo: poder local y regional en la Ciénaga de Chapala, Michoacán. Zamora-México: El Colegio de Michoacán.

Weingrod, Alex (1968). "Patrons, Patronage, and Polotical Parties". Comparative Studies in Society and History. Vol. 10. no 4, pp. 377-400.

Wolf, E. R. (1956). “Aspects of Group Relations in a Complex Society: Mexico". American Anthropologist, New Series, Vol. 58, no. 6, pp. 10651078. 